University of Nebraska - Lincoln

DigitalCommons@University of Nebraska - Lincoln

Papers in Physical Properties

Chemical and Biomolecular Engineering

Research and Publications

4-2-2006

Retrofit of Distillation Columns Using Thermodynamic Analysis

Yasar Demirel

University of Nebraska-Lincoln, ydemirel2@unl.edu

Follow this and additional works at: https://digitalcommons.unl.edu/chemengphysprop

Part of the Chemical Engineering Commons

Demirel, Yasar, "Retrofit of Distillation Columns Using Thermodynamic Analysis" (2006). Papers in Physical Properties. 6.

https://digitalcommons.unl.edu/chemengphysprop/6

This Article is brought to you for free and open access by the Chemical and Biomolecular Engineering Research and Publications at DigitalCommons@University of Nebraska - Lincoln. It has been accepted for inclusion in Papers in Physical Properties by an authorized administrator of DigitalCommons@University of Nebraska - Lincoln. 


\title{
Retrofit of Distillation Columns Using Thermodynamic Analysis
}

Comment: This paper is published in the Taylor \& Francis journal of "Separation science and Technology". And all the copy rights (C) of this paper belong to Taylor and Francis Group, LLC.

\begin{abstract}
Thermodynamic analysis provides the column grand composite curves and exergy loss profiles, which are becoming readily available for a converged distillation column simulation. For example, the Aspen Plus simulator performs the thermodynamic analysis through its Column-Targeting tool for rigorous column calculations. This study uses the column grand composite curves and the exergy loss profiles obtained from Aspen Plus to assess the performance of the existing distillation columns, and reduce the costs of operation by appropriate retrofits in a methanol plant. Effectiveness of the retrofits is also assessed by means of thermodynamics and economics. The methanol plant utilizes two distillation columns to purify the methanol in its separation Section. The first column operates with 51 stages, has a side heat stream to the last stage, a partial condenser at the top and a side condenser at stage 2, and no reboiler. The second column operates with 95 stages, has a side heat stream to stage 95 , a total condenser, and high reflux ratio. Despite the heat integration of the columns with the other Sections and a side condenser in column 1, the assessment of converged base case simulations have indicated the need for more profitable operations, and the required retrofits are suggested. For the first column, the retrofits consisting of a feed preheating and a second side condenser at stage 4 have reduced the total exergy loss by $21.5 \%$. For the second column, the retrofits of two side reboilers at stages 87 and 92 have reduced the total exergy loss by $41.3 \%$. After the retrofits, the thermodynamic efficiency has increased to $55.4 \%$ from $50.6 \%$ for the first column, while it has increased to $6.7 \%$ from $4.0 \%$ for the second. The suggested retrofits have reduced the exergy losses and hence the cost of energy considerably, and proved to be more profitable despite the fixed capital costs of retrofits for the distillation columns of the methanol plant.
\end{abstract}

Keywords: Thermodynamic analysis, column grand composite curves, exergy loss, retrofitting, thermodynamic efficiency. 


\section{Nomenclature}

$\begin{array}{ll}D & \text { Distillate, }\left(\mathrm{kmol} \mathrm{hr}^{-1}\right) \\ H & \text { Enthalpy }\left(\mathrm{J} \mathrm{mol}^{-1}\right) \\ Q & \text { Heat flow }(\mathrm{W}) \\ L & \text { Liquid flow rate }\left(\mathrm{kmol} \mathrm{hr}^{-1}\right) \\ m \cdot & \text { Mass flow rate }\left(\mathrm{kg} \mathrm{hr}^{-1}\right) \\ n & \text { Molar flow rate }\left(\mathrm{kmol} \mathrm{hr}^{-1}\right) \\ Q_{C} & \text { Condenser duty }(\mathrm{MW}) \\ Q_{R} & \text { Reboiler duty }(\mathrm{MW}) \\ S & \text { Entropy }(\mathrm{J} \text { mol } \\ T & \text { Temperature }(\mathrm{K}) \\ x & \text { Liquid mole fraction } \\ X & \text { Exergy (MW) } \\ y & \text { Vapor mol fraction } \\ V & \text { Vapor flow rate }(\mathrm{kmol} \mathrm{hr})\end{array}$

\section{Greek}

$\eta \quad$ Efficiency

$\lambda \quad$ Heat of vaporization $\left(\mathrm{J} \mathrm{mol}^{-1}\right)$

Subscripts

$\begin{array}{ll}\text { def } & \text { Deficit } \\ \text { D } & \text { Distillate } \\ \text { F } & \text { Feed } \\ \text { V } & \text { Vapor } \\ H & \text { Heavy } \\ L & \text { Light } \\ \text { min } & \text { Minimum } \\ R & \text { Reboiler } \\ S & \text { Stream, shaft }\end{array}$




\subsection{Introduction}

Retrofits suggest modifications for existing distillation columns to reduce the costs of operations by increasing the efficiency in energy utilization (1 $\underline{1}-\underline{7})$. Thermodynamic analysis (TA) is one of the methods for the retrofits. TA mainly seeks modification targets for reducing the thermodynamic losses due to heat and mass transfer, pressure drop, and mixing in an existing design and operation. As a result, for example in a binary distillation, operating curves come closer to the equilibrium curve, and reflux ratio approaches to its minimum value. However, the sharpness of multicomponent separation is limited, and close to reversible operating conditions may be more difficult to achieve (3). To analyze the performance of an existing column quantitatively for exploring the energy-saving potential, it is customary to construct the temperature enthalpy and stage-enthalpy curves, called the column grand composite curves (CGCC), and the stage exergy loss profiles $(\underline{1}, \underline{2}, \underline{7})$. The CGCC displays the net enthalpies for the actual and ideal operations at each stage, and the cold and hot heat utility requirements $(\underline{1}, \underline{3})$, while the exergy loss profiles indicate the level of irreversibility at each stage including the condenser and reboiler $(\underline{4}, \underline{8}-\underline{10})$. Therefore, the area between the actual and the ideal operations in a CGCC should be small, and exergy losses should be lower for a thermodynamically efficient operation. The CGCC is constructed by solving the mass and energy balances for a reversible column operation. The stage exergy loss profiles are generated by the stage exergy balance calculations with a reference temperature.

The CGCC and stage exergy loss profiles are becoming readily available $(\underline{7}, \underline{11}, \underline{16})$ even for multicomponent, complex distillation column operations such as crude oil distillation by a suitable simulation package $(\underline{5}, \underline{6}, \underline{12}, \underline{13})$. This enables the process engineer to assess an existing operation, and suggest suitable retrofits for reducing utility costs by improving efficiency in energy usage $(\underline{5}, \underline{6}, \underline{14})$. For design and retrofit purposes, the CGCC and exergy loss profiles can identify the targets for restructuring and modifications, and may be helpful in suggesting retrofits. Some of the retrofits consist of feed conditioning (preheating or precooling), feed splitting, reflux adjustments, and adding side condensers and reboilers. These retrofits target a practical near minimum thermodynamic loss $(\underline{1}, \underline{3})$. This study presents the use of the CGCC and exergy loss profiles generated by Aspen Plus to assess the existing operations, and suggest retrofits, if necessary, for the distillation columns in the separation Section of a methanol production plant. The separation section consists of two complex columns in series. The columns operate with multicomponent feeds and multiple side products, and use process heats as side heat streams from the other Sections of the plant. The first column operates with a side condenser, and has no reboiler. The estimated thermodynamic efficiencies and an approximate economical analysis are used to assess the e 


\subsection{Methanol Plant}

The methanol plant uses natural gas, carbon dioxide, and water as the basic feed streams, and produces $62000 \mathrm{~kg} / \mathrm{hr}$ and $99.95 \%$ pure methanol (15). The plant operates with five Sections connected to each other by the material and heat streams, as shown in Fig. 1: Brief descriptions of the Sections are as follows: Section 1 prepares the feeds of $24823 \mathrm{~kg} / \mathrm{hr}$ carbon dioxide at 1.4 bar and $43^{\circ} \mathrm{C}$, and $29952 \mathrm{~kg} / \mathrm{hr}$ natural gas containing 95.39 mole\% methane at $21.7 \mathrm{bar}$ and $26^{\circ} \mathrm{C}$. Also, there are the circulation water of $410000 \mathrm{~kg} / \mathrm{hr}$ at $26 \mathrm{bar}$ and $195^{\circ} \mathrm{C}$, and the makeup steam at 26 bar. By adjusting the steam flow rate, the steam to methane ratio of 2.8 is achieved in the reactor (reformer). Section 2 uses the reactor outlet (GAS1) as the feed, recovers the heat and water in the reformed gas using a series of heat exchangers and flash drums, and produces a $7312.3 \mathrm{kmol} / \mathrm{hr}$ and $99.75 \%$ vapor feed stream (SYNHP) at 82.5 bar and $40^{\circ} \mathrm{C}$. In Section 3, the methanol synthesis takes place in a tube-cooled reactor with an exit temperature of $240^{\circ} \mathrm{C}$. The main and some side reactions taking place in the reactor are

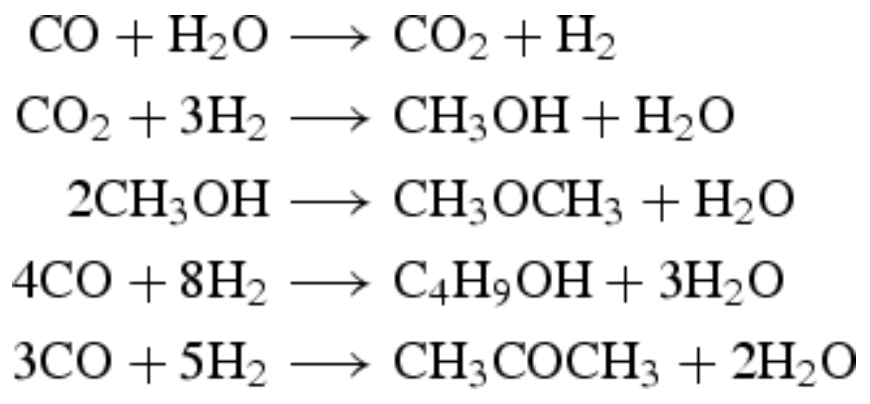

The reactor outlet contains small amounts of dimethylether, n-butanol, and acetone, beside the main product of methanol. The outlet is flashed and the methanol rich liquid stream 407 is fed to Section 4. Table 1 shows the properties and compositions of the outlet and stream 407. Separation of the methanol in Section 4 starts with flashing of stream 407 (feed 4) and continues further with the two distillation columns for purification, as seen in Fig. 2(a). The feed to the first column is the mixture of the liquid outlet of the flash drum and the makeup water at 5 bar and $40^{\circ} \mathrm{C}$, and enters at stage 14 . Flow rate of the makeup water is adjusted in order to minimize the methanol loss at the bottoms of the second column. The stages are numbered from the top to the bottom. The first column has 51 stages, a partial condenser at the top, and a side condenser at stage 2. It receives the feed at stage 14 , a side heat stream of $15.299 \mathrm{MW}$ at stage 51 , and operates without rebolier. A pumparound connects the liquid flow between stage 1 and 3 . The second column has 95 stages and a total condenser at the top. It receives the feed at stage 60 , a side heat stream of $18.9 \mathrm{MW}$ at stage 95 , and operates with high reflux ratio. The methanol is a side product of the second column drawn from stage 4 . The side heat streams come from 


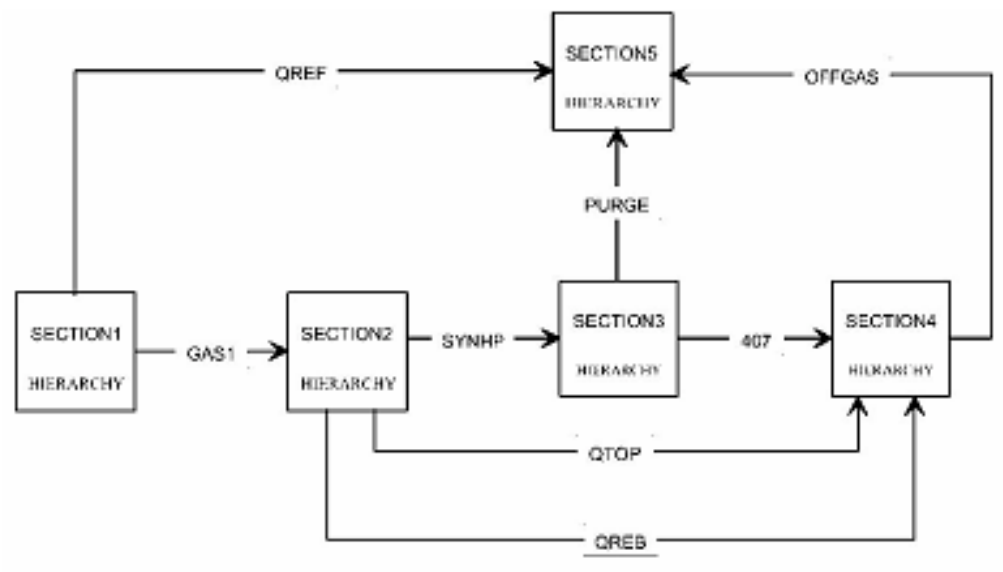

Section2 (Fig. 1). Section 5 is the furnace Section, where the offgas from Section 4 is burned.

Figure 1.Connection of the Sections of the methanol plant with material and heat streams

(a)

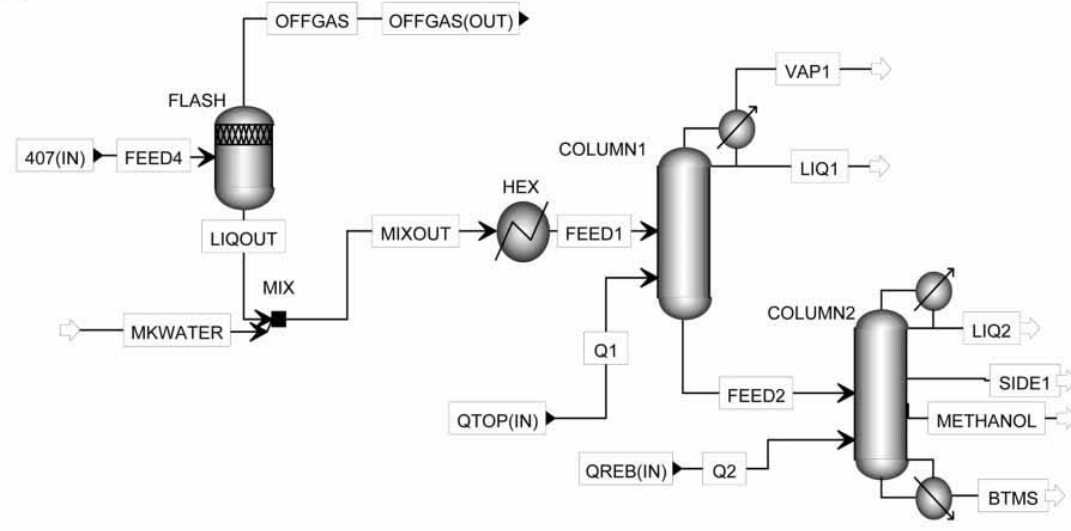

(b)

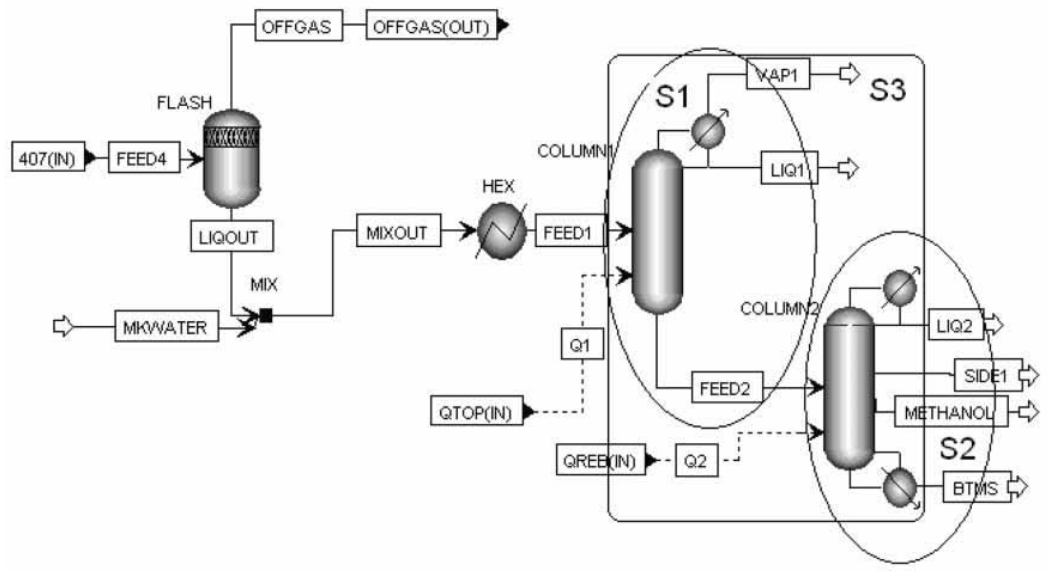

Figure 2. (a) Separation Section of the methanol plant, (b) Subsystems used in thermodynamic efficiency estimations:S1-column 1;S3-column 1 and 2. 
Table 1. Stream properties and compositions for the reactor output, the feeds, and methanol (See Fig. 2)

\begin{tabular}{ccccc}
$\begin{array}{c}\text { Methanol } \\
\text { reactor } \\
\text { output }\end{array}$ & $\begin{array}{c}\text { Flash drum } \\
\text { liquid } \\
\text { output } \\
\text { (Feed 4) }\end{array}$ & $\begin{array}{c}\text { Feed } \\
\text { Feed }\end{array}$ & $\begin{array}{c}\text { Fed } \\
\text { Methanol }\end{array}$ \\
\hline
\end{tabular}

\begin{tabular}{|c|c|c|c|c|c|}
\hline $\begin{array}{l}\text { Temperature, } \\
{ }^{\circ} \mathrm{C}\end{array}$ & 258.5 & 45.0 & 43.7 & 85.8 & 75.1 \\
\hline Pressure, bar & 83.0 & 75.6 & 5.0 & 1.8 & 1.5 \\
\hline $\begin{array}{l}\text { Vapor } \\
\text { fraction }\end{array}$ & 1.0 & - & - & - & - \\
\hline$n \cdot, \mathrm{kmol} / \mathrm{hr}$ & 27170.06 & 2655.32 & 3029.28 & 2995.14 & 1925.59 \\
\hline \multicolumn{6}{|c|}{ Mole fractions } \\
\hline $\mathrm{CO}$ & $2.988 \mathrm{E}-02$ & $1.547 \mathrm{E}-04$ & $\begin{array}{c}1.562 \mathrm{E}- \\
06\end{array}$ & $\begin{array}{c}5.198 \mathrm{E}- \\
27\end{array}$ & $0.000 \mathrm{E}+00$ \\
\hline $\mathrm{CO}_{2}$ & $1.060 \mathrm{E}-01$ & $2.557 \mathrm{E}-02$ & $\begin{array}{c}8.777 \mathrm{E}- \\
03\end{array}$ & $\begin{array}{c}1.917 \mathrm{E}- \\
24\end{array}$ & $0.000 \mathrm{E}+00$ \\
\hline Hydrogen & 4.559E-01 & $1.082 \mathrm{E}-03$ & $\begin{array}{c}4.687 \mathrm{E}- \\
06\end{array}$ & $\begin{array}{c}1.407 \mathrm{E}- \\
26\end{array}$ & $0.000 \mathrm{E}+00$ \\
\hline Water & $2.300 \mathrm{E}-02$ & $2.300 \mathrm{E}-01$ & $\begin{array}{c}3.481 \mathrm{E}- \\
01\end{array}$ & $\begin{array}{c}3.521 \mathrm{E}- \\
01\end{array}$ & $2.173 \mathrm{E}-20$ \\
\hline Methanol & $7.828 \mathrm{E}-02$ & 7.345E-01 & $\begin{array}{c}6.422 \mathrm{E}- \\
01\end{array}$ & $\begin{array}{c}6.476 \mathrm{E}- \\
01\end{array}$ & $1.000 \mathrm{E}+00$ \\
\hline Methane & $3.035 \mathrm{E}-01$ & $8.055 \mathrm{E}-03$ & $\begin{array}{c}4.273 \mathrm{E}- \\
04\end{array}$ & $\begin{array}{c}1.000 \mathrm{E}- \\
33\end{array}$ & $0.000 \mathrm{E}+00$ \\
\hline Nitrogen & $3.225 \mathrm{E}-03$ & $3.858 \mathrm{E}-05$ & $\begin{array}{c}9.021 \mathrm{E}- \\
07\end{array}$ & $\begin{array}{c}1.362 \mathrm{E}- \\
21\end{array}$ & $0.000 \mathrm{E}+00$ \\
\hline Butanol & $3.100 \mathrm{E}-05$ & $3.008 \mathrm{E}-04$ & $\begin{array}{c}2.633 \mathrm{E}- \\
04\end{array}$ & $\begin{array}{c}2.663 \mathrm{E}- \\
04\end{array}$ & $1.419 \mathrm{E}-35$ \\
\hline $\begin{array}{l}\text { Dimethyl } \\
\text { ether }\end{array}$ & $6.342 \mathrm{E}-05$ & $5.835 \mathrm{E}-05$ & $\begin{array}{c}3.857 \mathrm{E}- \\
05\end{array}$ & $\begin{array}{c}5.678 \mathrm{E}- \\
21\end{array}$ & $0.000 \mathrm{E}+00$ \\
\hline Acetone & $2.066 \mathrm{E}-05$ & $1.100 \mathrm{E}-04$ & $\begin{array}{c}9.413 \mathrm{E}- \\
05\end{array}$ & $\begin{array}{c}1.119 \mathrm{E}- \\
06\end{array}$ & $1.740 \mathrm{E}-06$ \\
\hline Ethane & $6.158 \mathrm{E}-06$ & $6.135 \mathrm{E}-07$ & $\begin{array}{c}1.163 \mathrm{E}- \\
07\end{array}$ & $\begin{array}{c}1.000 \mathrm{E}- \\
33\end{array}$ & $0.000 \mathrm{E}+00$ \\
\hline Propane & $4.851 \mathrm{E}-10$ & $1.034 \mathrm{E}-10$ & $\begin{array}{c}3.588 \mathrm{E}- \\
11\end{array}$ & $\begin{array}{c}1.000 \mathrm{E}- \\
33\end{array}$ & $0.000 \mathrm{E}+00$ \\
\hline
\end{tabular}




\subsection{Thermodynamic Analysis (TA)}

In every nonequilibrium system, an entropy effect leading to energy dissipation or exergy loss exists either within or through the boundary of a system. TA combines the first and second laws of thermodynamics, and determines the net enthalpy deficits as well as the losses of available energy called the exergy losses due to irreversibilities at each stage of a column. The distributions of the enthalpy deficits and exergy losses can identify the scope and extent of modification targets or retrofits for improvements by reducing the irreversibilities economically $(\underline{12}, \mathrm{~T} \underline{14}, \underline{17}-\underline{19})$ as well as distributing them evenly $(\underline{4}, \underline{7}, \underline{9}, \underline{10})$. Whether a retrofit is economical or not would only be known after an overall optimization, which seeks the best solution for a whole plant under specific constraints. Therefore, the relations between the energy efficiency and capital cost must be evaluated $(\underline{11}, \underline{12})$. In a simpler approach, one may estimate the trade offs between the costs of retrofits and savings due to the reduced exergy loss equivalent of fuel or electricity. TA is of considerable value when an efficient energy conversion is important, and becomes an environmental concern.

Normally, distillation columns operate with inevitable thermodynamic losses due to mixing, heat and mass transfer causing finite separations, pressure drops, internal stage design, and configuration of columns, such as the numbers of feeds and side products. A 'practical nearminimum thermodynamic condition' (1) targets reversible column operation with negligible entropy production. To achieve that, heaters and coolers with appropriate duties would operate at each stage; reflux ratio would be close to its minimum, and hence the operating lines approach the equilibrium curve. This would correspond to the distribution of reboiling and condensing loads throughout the column, and hence over the temperature range of operation. The ColumnTargeting tool of Aspen Plus ( $\underline{16})$ performs the thermal analysis, and produces the CGCC and the exergy loss profiles for rigorous column calculations based on the practical near-minimum thermodynamic condition. The enthalpy estimations take into account the thermodynamic losses due to column design and operating conditions, such as pressure drop, multiple feeds, and side products as well as side heat exchangers. For specified light and heavy key components, the equations. 


\subsection{Column Grand Composite Curve (CGCC)}

The stage-enthalpy and temperature-enthalpy profiles of CGCC represent the theoretical minimum heating and cooling requirements over the stages or the temperature range. Using the equilibrium compositions of light $L$ and heavy $H$ key components obtained from a converged simulation, minimum vapor, and liquid flow rates leaving the same stage with the same temperatures can be estimated from the following mass balances $(\underline{1}, \underline{3})$

$$
\begin{aligned}
& V_{\min }=\frac{1}{y_{L}^{*}}\left(D_{L}+L_{\min } x_{L}^{*}\right) \\
& L_{\min }=\frac{1}{x_{H}^{*}}\left(V_{\min } y_{H}^{*}-D_{H}\right)
\end{aligned}
$$

The enthalpies for the minimum vapor and liquid flows are obtained from the molar flow ratios

$$
\begin{aligned}
& H_{\mathrm{Vmin}}=H_{V}^{*}\left(\frac{V_{\min }}{V^{*}}\right) \\
& H_{\mathrm{Lmin}}=H_{L}^{*}\left(\frac{L_{\min }}{L^{*}}\right)
\end{aligned}
$$

where $V^{*}$ and $L^{*}$ are the molar flows of equilibrium, and $H_{V^{*}}$ and $H_{L}{ }^{*}$ are the enthalpies of equilibrium vapor and liquid streams leaving the same stage, respectively. From the enthalpy balances at each stage, the net enthalpy deficits are obtained (1)

$$
\begin{aligned}
& H_{\text {def }}=H_{\mathrm{Lmin}}-H_{\mathrm{V} \min }+H_{D} \quad \text { (before the feed stage) } \\
& H_{\text {def }}=H_{\mathrm{L} \text { min }}-H_{\mathrm{V} \text { min }}+H_{D}-H_{\text {feed }} \quad \text { (after the feed stage) }
\end{aligned}
$$

After adding the individual stage enthalpy deficits to the condenser duty, the enthalpy values are cascaded, and plotted in the CGCC. This is called the top-down calculation procedure, which will be the same with the bottom-up calculations for a stage without any feed $(\underline{1}, \underline{3})$. At the feed stage, mass and energy balances differ from a stage without feed, and finite changes of composition and temperature disturbs the reversible operation. For the two procedures to yield similar results, the enthalpy deficit at the feed stage becomes ( $\underline{3})$ 


$$
\begin{aligned}
H_{\mathrm{def}, \mathrm{F}}= & Q_{C}+D\left[H_{D}+H_{L}\left(x_{D}-y_{F}^{*}\right) /\left(y_{F}^{*}-x_{F}^{*}\right)\right. \\
& \left.-H_{V}\left(x_{D}-x_{F}^{*}\right) /\left(y_{F}^{*}-x_{F}^{*}\right)\right]
\end{aligned}
$$

The values of $y_{F}^{*}$ and $x_{F}^{*}$ may be obtained from an adiabatic flash for a single phase feed, or from the constant relative volatility estimated with the converged compositions at the feed stage and feed quality. This procedure can be reformulated for multiple feeds and side products as well as different choices of the key components (프). In a CGCC, a pinch point near the feed stage occurs for nearly binary ideal mixtures. However, for nonideal multicomponent systems pinch exists in rectifying and stripping Sections.

A horizontal distance between the CGCC pinch point and the vertical axis represents the excess heat, and therefore the scope for reduction in reflux ratio $(\underline{1}-\underline{3}, \underline{16})$. For smaller reflux ratios, the CGCC will move towards the vertical axis, and hence reduce the reboiler and condenser duties, which may be estimated by $(\underline{3})$

$$
\begin{aligned}
Q_{R}-Q_{R, \min } & =Q_{C}-Q_{C, \min } \\
& =D \lambda\left[R-\left(x_{D}-y_{F}^{*}\right) /\left(y_{F}^{*}-x_{F}^{*}\right)\right]
\end{aligned}
$$

where $\lambda$ is the heat of vaporization. The horizontal distance of the CGCC from the temperature axis, however, determines the targets for installing a side reboiler or side condenser at suitable temperatures $(\underline{1}, \underline{2}, \underline{16}, \underline{17})$. On the other hand, a sharp change in the enthalpy represents inappropriate feed conditioning, such as feed quality or temperature. For example, a sharp change on the reboiler side may be due to a subcooled feed, and a feed preheater with a heat duty depending on the change can be installed $(\underline{1}, \underline{2}, \underline{16}, \underline{18})$. Feed conditioning is usually preferred to side condensing or reboiling, since the side heat exchangers are effective at suitable temperature levels or stages only $(\underline{1}, \underline{2}, \underline{17}, \underline{18})$.

\subsection{Exergy Loss Profiles}

Exergy losses represent inefficient use of available energy due to irreversibility, and should be reduced by suitable retrofits $(\underline{5}, \underline{7}, \underline{12}, \underline{14})$. Exergy $X\left(X=H-T_{0} S\right)$ shows the available energy that can be converted into a useful work in a reversible process based on a reference temperature $T_{o}$, which is usually assumed as the environmental temperature of $298.15 \mathrm{~K}$.

For a steady state system, energy balance is 


$$
\sum_{\substack{\text { out of } \\ \text { system }}}\left(\dot{n} H+\dot{Q}+\dot{W}_{s}\right)-\sum_{\substack{\text { into } \\ \text { system }}}\left(\dot{n} H+\dot{Q}+\dot{W}_{s}\right)=0
$$

Exergy balance for a steady state system shows that exergy is not conserved

$$
\begin{aligned}
\sum_{\substack{\text { into } \\
\text { system }}}\left[\dot{n} X+\dot{Q}\left(1-\frac{T_{o}}{T_{s}}\right)+\dot{W}_{s}\right] \\
\quad-\sum_{\substack{\text { out of } \\
\text { system }}}\left[\dot{n} X+\dot{Q}\left(1-\frac{T_{o}}{T_{s}}\right)+\dot{W}_{s}\right]=\dot{X}_{\text {loss }}
\end{aligned}
$$

where $W_{s}^{\cdot}$ is the shaft work. The rate of loss exergy $X_{\text {loss }}$ represents the overall thermodynamic imperfections, and directly proportional to the rate of entropy production due to irreversibility's in a column operation. As the exergy loss increases, the net heat duty has to increase to enable the column to achieve a required separation. Consequently, smaller exergy loss means less waste heat or thermodynamic imperfections, which include pressure drop, heat and mass transfer due to finite driving forces, and mixing of flows with different compositions and temperatures.

For distillation columns, the difference between the exergies of products and feed streams determines the minimum exergy (separation work) necessary for a required separation

$$
\dot{X}_{\min }=\sum_{\text {out }} \dot{n} X-\sum_{\text {in }} \dot{n} X
$$

A conventional column receives heat at a higher temperature level in the reboiler, and discharges about the same amount in the condenser at a lower temperature. Therefore, it resembles a heat engine that produces the separation work. For a reversible distillation column, Carnot factors in Eq. 10 describe the maximum work available from a heat source.

When $X_{\text {min }}^{\cdot}>0$, thermodynamic efficiency becomes 


$$
\eta=\frac{\dot{X}_{\text {min }}}{\dot{X}_{\text {loss }}+\dot{X}_{\min }}
$$

The denominator in Eq. (12) is the total exergy input. The values of efficiencies before and after the retrofits can quantify the improvements, and help assessing the effectiveness of retrofits

\subsection{Results and Discussion}

Synthesis of the methanol takes place in a tube reactor in Section 3. The reactor outlet is flashed at $45^{\circ} \mathrm{C}$ and 75 bar, and the liquid product (stream 407) containing 73.45 mole $\%$ of methanol is fed into the separation Section, where the methanol is purified. Stream 407 and the makeup water are the feed streams to the Section. Table 1 shows the properties and compositions of the streams, while Tables 2 and $\underline{3}$ describe the existing base case column operations. The converged simulations use the thermodynamic method of Redlich-Kwong-Soave (RKW) to estimate the vapor properties, while the activity coefficient model NRTL and Henry components method are used for predicting the equilibrium and liquid properties. The stages are numbered starting from the condenser, and the vapor and liquid phases leaving the same stage are in equilibrium with each other. The assessments of the performances of existing columns, suggested retrofits, and the effectiveness of the retrofits with minimum or no change in the column pressure and the stage numbers are discussed below.

\section{Column 1}

As the base case design in Table 2 shows, column 1 has 51 stages, and operates with a partial condenser with a duty of $1.371 \mathrm{MW}$ at the top, and a side condenser with a duty of $8.144 \mathrm{MW}$ at stage 2. It has no reboiler, however, it receives a side heat stream with a duty of $15.299 \mathrm{MW}$ to the last stage from Section 2 of the plant. The temperature and concentration profiles in Fig. 3 show that column 1 is practically a binary rectification column having the feed close to the top at stage 14, although the feed is a multicomponent mixture (Table 1). 
(a)

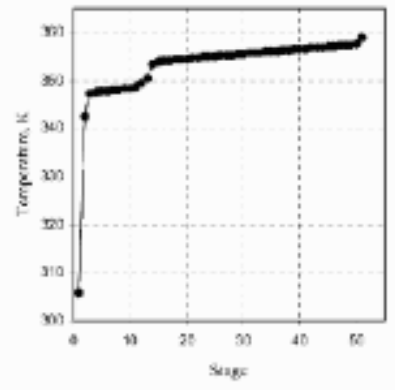

(b)

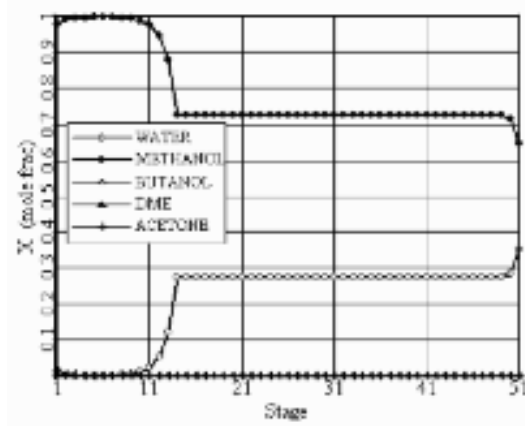

Figure 3. (a) Temperature profile, and (b) liquid mole fraction profile for column 1.

Table 2. Comparison of operating parameters of designs 1 and 2 for column 1

\section{Parameter}

No. of stages

Feed stage

Feed temperature, ${ }^{\circ} \mathrm{C}$

Reflux ratio

Condenser duty, MW

Distillate rate, $\mathrm{kmol} \mathrm{hr}^{-1}$

Condenser temperature, ${ }^{\circ} \mathrm{C}$

Side condenser 1 stage

Side condenser 1 duty, MW

Stage 2 temperature, ${ }^{\circ} \mathrm{C}$

Side condenser 2 stage

Side condenser 2 duty, MW

Stage 4 temperature, ${ }^{\circ} \mathrm{C}$

Heat stream (Q1) duty, MW

Heat stream (Q1) stage

\section{Design 1 (base case) Design 2 (retrofitted)}

51

14

43.7

3.7

1.372

34.14

32.7

8.144

69.4

-

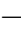

74.4

15.299

51
51

14

65.0

4.5

1.691

34.14

32.7

2

7.700

70.3

4

2.100

74.4

15.299

51 
Table 3. Comparison of operating parameters of designs 1 and 2 for column 2

\section{Parameter}

Design 1 (base case) Design 2 (retrofitted)

\section{No. of stages}

Feed stage

Feed temperature, ${ }^{\circ} \mathrm{C}$

Reflux ratio

Condenser duty, MW

Distillate rate, $\mathrm{kmol} \mathrm{hr}^{-1}$

Condenser temperature, ${ }^{\circ} \mathrm{C}$

Reboiler duty, MW

Boilup rate, $\mathrm{kmol} \mathrm{hr}^{-1}$

Bottoms rate, $\mathrm{kmol} \mathrm{hr}^{-1}$

Reboiler temperature, ${ }^{\circ} \mathrm{C}$

Side reboiler 1 stage

Side reboiler 1 duty, MW

Stage 87 temperature, ${ }^{\circ} \mathrm{C}$

Side reboiler 2 stage

Side reboiler 2 duty, MW

Stage 92 temperature, ${ }^{\circ} \mathrm{C}$

Heat stream (Q2) duty, MW

Heat stream (Q2) stage

Heat stream $(\mathrm{Q} 2)$ temperature, ${ }^{\circ} \mathrm{C}$
95

60

85.8

188765.0

281.832

0.15

74.8

282.283

24890.68

1050.96

119.7

-

$$
\text { - }
$$

90.9

-

-

110.9

18.900

95

136.0
95

60

85.8

188765.0

281.832

0.15

74.8

52.292

4633.93

1049.66

120.0

87

180.000

93.3

92

50.000

110.9

18.900

95

136.0 
The temperature-enthalpy CGCC, and the temperature and composition profiles may help assessing the operation and determining the extent and position of side heating or condensing for the column. The CGCC in Fig. 4 shows that; within the rectification Section, there exists a significant area difference between the ideal and actual enthalpy profiles, which identifies the scope for side condensing. As the temperature change after stage 3 is very small, and a side condenser at stage 2 already exists, it has been decided to install second side condenser at stage 4 with a duty of 2.1 MW. As Fig. 4(b) shows, the side condenser has reduced the area between the ideal and actual enthalpy profiles. Figure 5 also shows that the actual vapor flow closely follows the thermodynamic ideal minimum vapor flow on stages 2,3 , and 4 after the retrofit. The duty of 2.1 MW is in the range of enthalpy difference between the hot duty of 15.299 MW and the total cold duty of 9.51 MW (side condenser+partial condenser shown in Table 2). The existing side condenser duty is reduced to $7.7 \mathrm{MW}$ from $8.144 \mathrm{MW}$, so that the new total duty of $11.49 \mathrm{MW}$ is close to the previous total of $9.51 \mathrm{MW}$. After the retrofit, therefore, the total costs would not change too much, and the need for extra stages would be negligible as the heat changes sharply below the first side condenser.

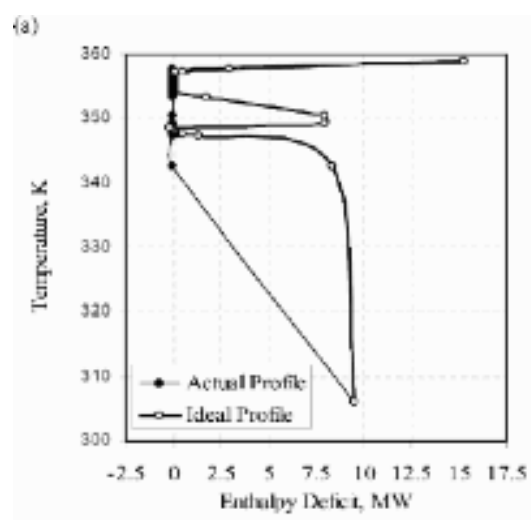

Figure 4. Temperature-enthalpy deficit curves (CGCC) for column 1: (a) design 1, (b) design 2. (Table 2 describes the designs 1 and 2 ).

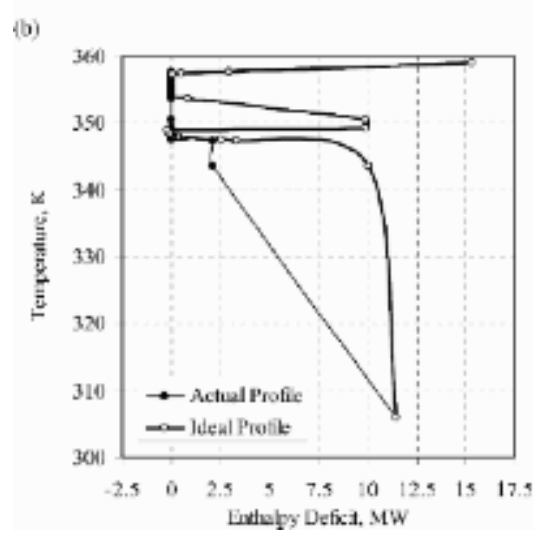




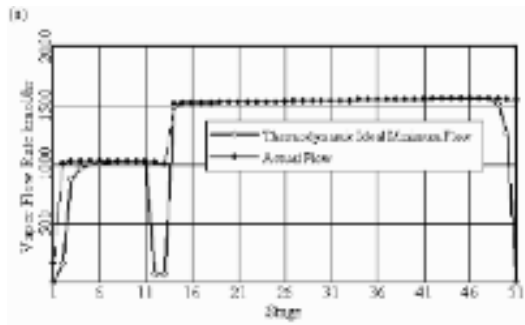

Figure 5. Vapor flow profiles of column 1: (a) design 1, (b)

design 2. (Table 2 describes the designs 1 and 2 ).

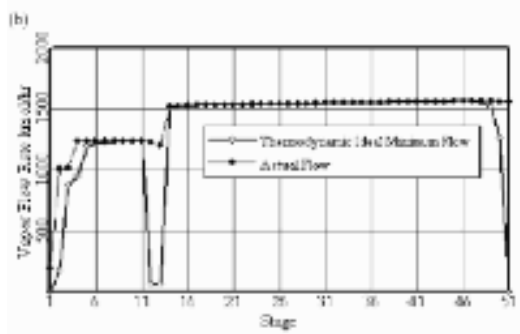

Since side heat exchangers are more effective at convenient temperature levels or stages for exchanging heat using cheaper utility, care should be exercised for positioning them. Agrawal and Herron (17) have suggested some heuristics for positioning side heat exchangers based on the feed concentrations and quality for binary distillation columns. Another approach may be based on the uniform distribution of the driving forces that cause the separation, leading to less entropy production and hence less exergy loss in the column where the coupling of heat and mass transfer may not be negligible $(\underline{4}, \underline{10}, \underline{13})$.

Figure 4 also displays a sharp change of the enthalpy on the reboiler side. The extent of the change determines the approximate feed preheating duty required, $(\underline{1}, \underline{2}, \underline{17}, \underline{18})$ as the feed at $43.74^{\circ} \mathrm{C}$ is highly subcooled (Table 2). Therefore, a new heat exchanger (HEX, in Fig. 2) with a duty of $1.987 \mathrm{MW}$ is used as the second retrofit for the column, and the feed temperature has increased to $65.0^{\circ} \mathrm{C}$ from $43.74^{\circ} \mathrm{C}$. Figure 6 compares the enthalpies for the base case and retrofitted designs. The difference between the hot and cold duties is lower, and the actual and ideal profiles are closer to each other after the retrofits. 
(a)

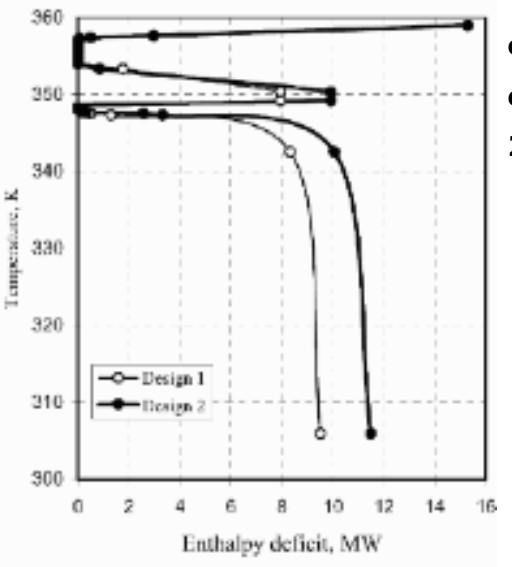

(b)

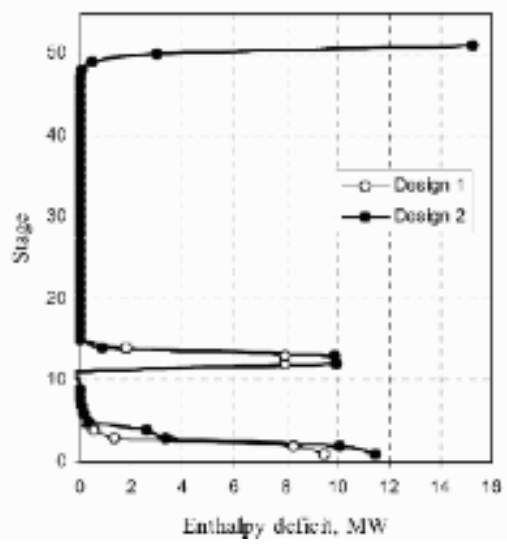

Figure 6. The column grand composite curves (CGCC) for column 1: (a) temperature-enthalpy deficit curves, (b) stageenthalpy deficit curves. (Table 2 describes the designs 1 and 2).

The suggested retrofits also aim at reducing the irreversibility due to mixing of the streams at different temperatures on the feed stage, which is at $80.18^{\circ} \mathrm{C}$, and throughout the column. The exergy loss profiles of Figs. 7 show that the reduction in exergy loss at the feed stage is about $60 \%$ with the values of $0.3865 \mathrm{MW}$ in design 1 and $0.1516 \mathrm{MW}$ in design 2 . However, the exergy loss at the partial condenser increases by $28 \%$, and becomes $0.150 \mathrm{MW}$ in design 2 instead of $0.117 \mathrm{MW}$ in design 1. As Table 5 shows, the reduction in the total exergy loss or the recovered available energy is $21.5 \%$ with the total column exergy losses of $0.837 \mathrm{MW}$ and $0.656 \mathrm{MW}$ in design 1 and 2, respectively. Table 2 compares the base case design and the retrofitted design. 
(a)

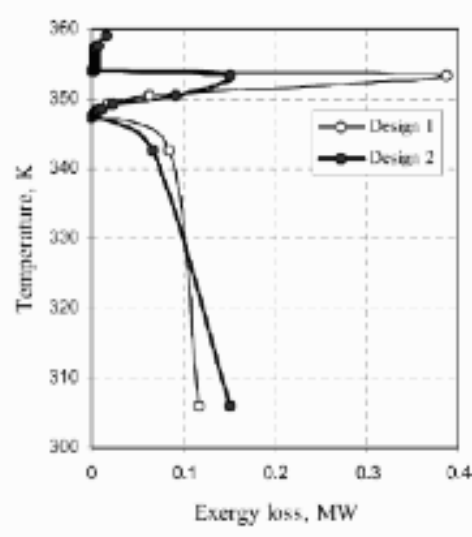

(b)

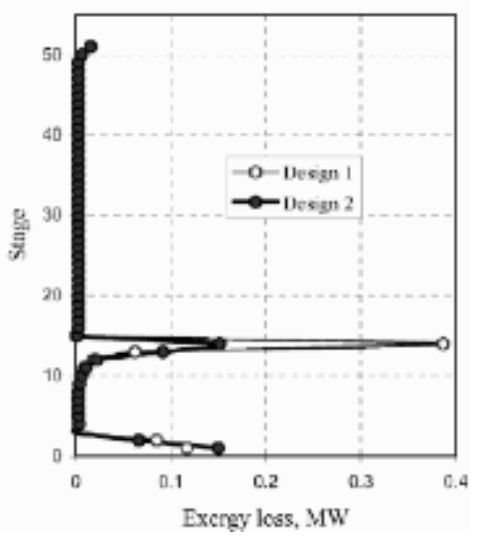

Figure 7. Exergy loss profiles for column 1: (a) temperature-exergy loss profiles, (b) stage-exergy loss profiles. (Table 2 describes the designs 1 and 2 ).

\section{Column 2}

As the base case design in Table 3 shows, column 2 has 95 stages, and a total condenser with a duty of $281.832 \mathrm{MW}$. It operates with a high reflux ratio, and receives a side heat stream of 18.9 MW to the last stage from Section 2 of the plant. One of the side products is the methanol stream described in Table 1, and drawn at stage 4 at $348.3 \mathrm{~K}$. The second side product is drawn at stage 86 at $361.2 \mathrm{~K}$. Temperature and concentration profiles in Fig. 8 shows that the separation system resembles a stripping column having the feed (Table 1) close to the bottom at stage 60 . The temperature profile increases sharply after stage 84 . 
(a)

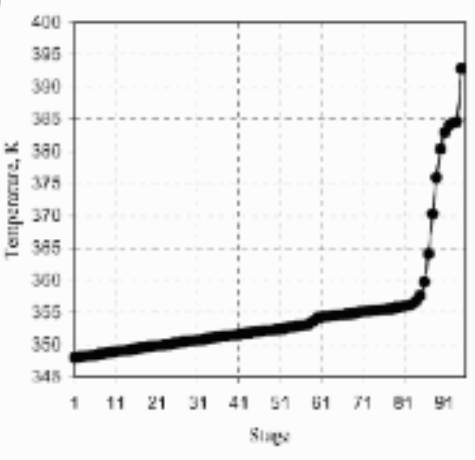

(b)

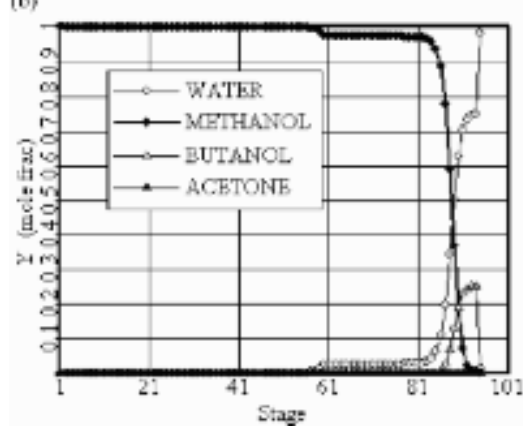

Figure 8. (a) Temperature profile, and (b) liquid mole fraction profiles for column 2.

Fig. 9(a) shows a significant area difference between the ideal and the actual enthalpy profiles above the feed stage representing the pinch, and hence suggests side reboiling at appropriate temperature levels to decrease the difference. The existing reboiler duty is $282.28 \mathrm{MW}$ (Table 3). Beside that there is a side product at stage 86 and a side heat inlet of $18.9 \mathrm{MW}$ at stage 95 . Therefore, it has been decided to install two side reboilers at stages 87 and 92 with the duties of 180 and $50 \mathrm{MW}$, respectively. Obviously, these two side reboilers would be more economical as they would operate at lower temperatures and need less expensive steams compared with the steam used in the existing reboiler. With the two side reboilers, the duty of the reboiler decreases to 52.3 MW from 282.3 MW. Extra stages due to the side reboilers would be minimal since the enthalpy rises sharply at each stage after stage 84 . Figure 9(b) shows a considerable reduction in the area between the ideal and actual enthalpy profiles after the retrofits. Moreover, the side reboilers have reduced the gap between the ideal and actual vapor flows between the stages 84 and 95, where the stage temperatures change sharply (Fig. 10). The enthalpy curves in Fig. 11 also displays that the retrofitted design is closer to ideal operation compared with that of design 1. 


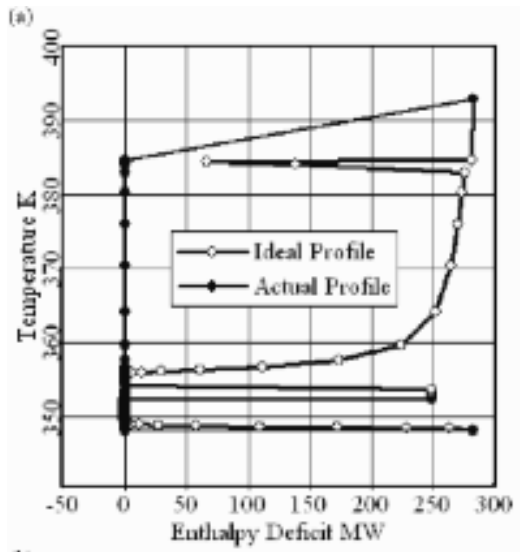

Figure 9. Temperature-enthalpy deficit curves (CGCC) for column 2: (a) design 1, (b) design 2. (Table 3 describes the designs 1 and 2 ).
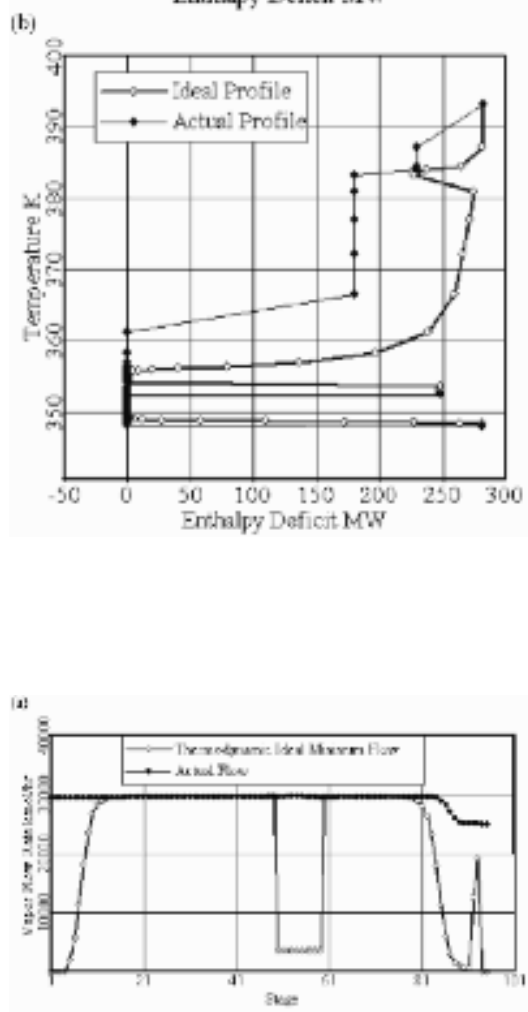

Figure 10. Vapor flow profiles for column 2: (a) design 1, (b) design 2. (Table 3 describes the designs 1 and 2 ).

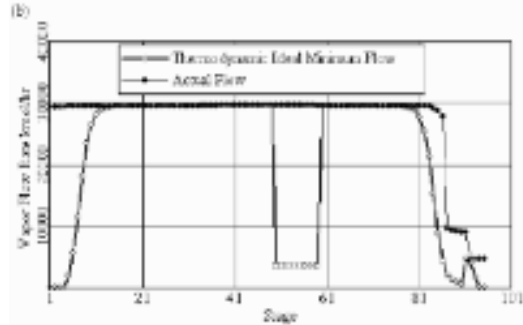


(a)

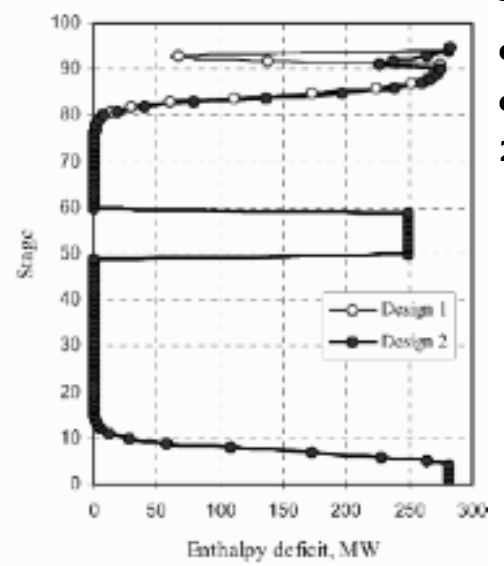

(b)

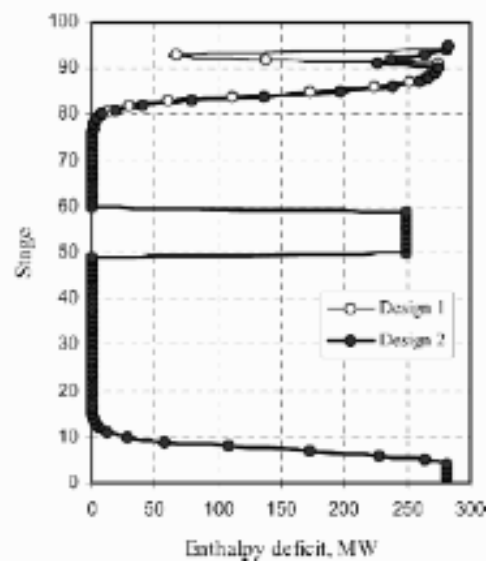

Figure 11. The column grand composite curves (CGCC) for column 2: (a) temperature-enthalpy deficit curves, (b) stageenthalpy deficit curves. (Table 3 describes the designs 1 and 2).

Figure 12 compares the exergy loss profiles in designs 1 and 2 . The base case design operates with rather large exergy losses at the feed stage and around the reboiler. The rest of the column has the negligible exergy losses mainly due to the flat methanol concentration profile. The retrofits reduce the total exergy losses by about $41.3 \%$, and hence save a considerable amount of the available energy. Figure 13 compares the temperature profiles of the last ten stages; the profiles in design 2 are slightly elevated, and the flat distribution around stage 93 has been removed by the retrofits. Table 3 compares the two designs of the column. 
(a)

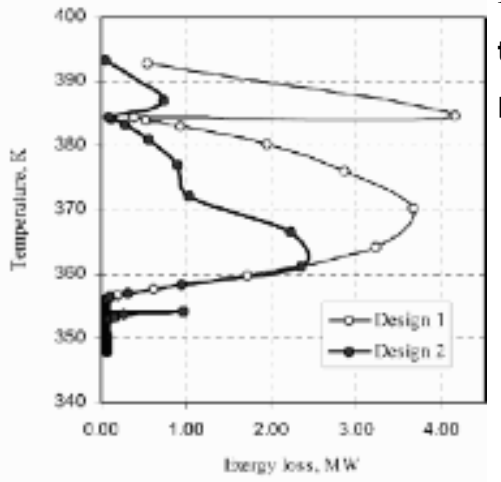

(b)

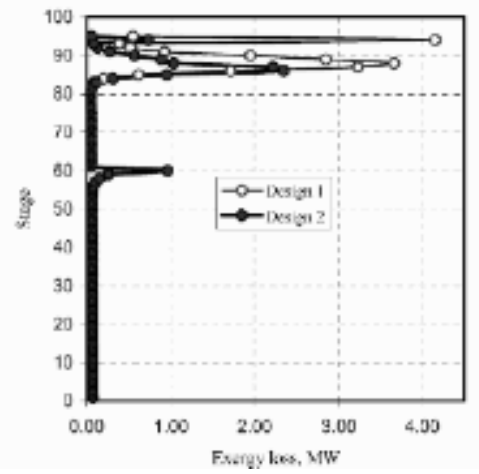

Figure 12. Exergy loss profiles for column 1: (a) temperature-exergy loss profiles, (b) stage-exergy loss profiles. (Table 3 describes the designs 1 and 2 ).

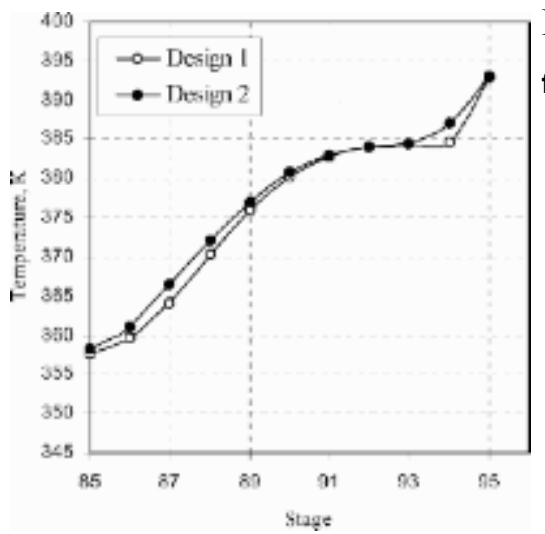

Figure 13. Temperature profile between stages 85 and 95 for column 2.

Table 4 lists the properties and compositions of the material streams obtained from the converged simulation by Aspen Plus within the boundary of the separation Section (Fig. 2b). Using the data from Table 4, the minimum values of exergy for the required separation and the thermodynamic efficiencies for designs 1 and 2 are estimated using Eqs. (11) and (12), and compared in Table 5. The estimations are based on the value $T_{o}=298.15 \mathrm{~K}$. Figure $2(\mathrm{~b})$ identifies the subsystems considered in Table 5. The reductions in the exergy losses range from $21.5 \%$ to 41.35\%. The thermodynamic efficiencies have increased considerably in the retrofitted designs, although the efficiencies are low, which are common for industrial column operations ( $\underline{8})$. For column 1 the efficiency increases to $55.4 \%$ from $50.6 \%$, while the efficiency increases to $6.7 \%$ from $4.0 \%$ in column 2 . 
Table 4. Material and heat streams for the separation Section of the plant (see Fig. 2)

\begin{tabular}{|c|c|c|c|c|c|c|c|}
\hline Stream & $\begin{array}{c}n^{*} \\
\text { (kmol/hr) }\end{array}$ & $\begin{array}{c}m^{*} \\
(\mathrm{~kg} / \mathrm{hr})\end{array}$ & $\begin{array}{c}T \\
(\mathrm{~K})\end{array}$ & $\begin{array}{c}H \\
(\mathrm{~kJ} / \mathrm{mol})\end{array}$ & $\begin{array}{c}H \\
(\mathrm{MW})\end{array}$ & $\begin{array}{c}S \\
(\mathrm{~J} / \mathrm{mol}- \\
\mathrm{K})\end{array}$ & $\begin{array}{c}X^{a} \\
(\mathrm{~kJ} / \mathrm{mol})\end{array}$ \\
\hline \multicolumn{8}{|l|}{${ }^{a} T_{o}=298.15 \mathrm{~K}$} \\
\hline FEED4 & 2655.32 & 76938.66 & 318.15 & -252.82 & -186.50 & -215.49 & -188.44 \\
\hline MKWATER & 444.21 & 8002.62 & 313.15 & -287.73 & -355.00 & -166.95 & -237.77 \\
\hline BTMS & 1050.96 & 18955.20 & 393.17 & -278.46 & -81.29 & -142.06 & -235.93 \\
\hline LIQOUT & 2584.80 & 74607.84 & 318.85 & -258.79 & -181.24 & -219.15 & -187.05 \\
\hline SIDE1 & 18.43 & 550.00 & 359.77 & -244.99 & -1.25 & -207.77 & -182.88 \\
\hline LIQ2 & 0.15 & 5.00 & 348.00 & -233.10 & -0.01 & -224.70 & -165.97 \\
\hline VAP1 & 33.80 & 1388.90 & 305.91 & -347.23 & -3.26 & -21.15 & -340.66 \\
\hline FFGAS & 70.25 & 2330.66 & 318.86 & -268.66 & -5.24 & -32.75 & -258.69 \\
\hline METHANOL & 1925.59 & 61700.40 & 348.29 & -233.07 & -124.70 & -224.60 & -165.97 \\
\hline LIQ1 & 0.34 & 11.10 & 305.91 & -239.07 & -0.02 & -237.28 & -168.19 \\
\hline FEED2 & 2995.14 & 81210.60 & 359.00 & -249.61 & -207.70 & -192.77 & -192.00 \\
\hline FEED1 & 3029.28 & 82610.60 & 323.15 & -256.89 & -216.20 & -208.38 & -194.68 \\
\hline Q1 & - & - & 377.00 & - & 15.29 & - & 3.19 \\
\hline Q2 & - & - & 409.00 & - & 18.90 & - & 5.12 \\
\hline
\end{tabular}

Table 5. Assessment of the effectiveness of the retrofits: minimum exergy of separation and thermodynamic efficiency estimations based on the converged simulation. The subsystems S1 to S3 are shown in Fig. 2(b) 


\section{Design 1 (base}

case)

\section{Design 2 (retrofitted)}

$\begin{array}{ccccccccccc}\text { System } & & & & & & & \text { Saved } & & \text { FCC }^{a} \text { of } & \text { Electricity } \\ & X_{\min } & X_{\text {loss }} & & X_{\min } & X_{\text {loss }} & \eta & X_{\text {loss }} & X_{\text {loss } \%} & \text { retrofits } & \text { saving }^{b} \\ (\mathrm{MW}) & (\mathrm{MW}) & & (\mathrm{MW}) & (\mathrm{MW}) & \% & (\mathrm{MW}) & & \$ & \text { (\$/year) }\end{array}$

$X_{\text {loss: }}$ Total column exergy loss from the converged simulation by Aspen Plus with SRK, NRTL, and Henry components methods.

${ }^{a}$ FCC: Fixed capital cost.

${ }^{e}$ lectricity equivalent of energy saving is based on a unit cost of electricity of $\$ 0.060 / \mathrm{kW}-\mathrm{hr}$.

\begin{tabular}{lcccccccccc} 
S1 & 0.856 & 0.837 & 50.6 & 0.815 & 0.656 & 55.4 & 0.179 & 21.5 & 183,500 & 89,578 \\
Column 1 & & & & & & & & & & \\
S2 & & & & & & & & & & \\
Column 2 & 1.136 & 26.979 & 4.0 & 1.135 & 15.847 & 6.7 & 11.133 & 41.3 & 409,000 & $5,558,829$ \\
S3 & & & & & & & & & & \\
Column & 1.992 & 27.814 & 6.7 & 1.950 & 16.502 & 10.6 & 11.312 & 40.7 & 592,500 & $5,648,407$ \\
$1+2$ & & & & & & & & & & \\
\hline
\end{tabular}

An approximate economic analysis has compared the fixed capital costs (FCC) of the retrofits with the savings in electricity due to the reduced exergy losses. FCC consists of equipment cost, materials, construction, and labor. Table 6 shows the approximate values of FCC for the heat exchangers needed in the retrofits. The costs are estimated by using the current chemical engineering plant cost index (20) of 420, and the approximate areas for the heat transfer obtained from the individual duties. The energy saving estimations are based on the unit cost of electricity of $\$ 0.060 / \mathrm{kW}-\mathrm{hr}$ and a total 8322 hours/year of the plant operation. The costs of related retrofits and the yearly saved exergy equivalent of electricity for each subsystem are compared in Table 5, which shows that the retrofits are effective and save a considerable amount of energy in electricity per year. 


\begin{tabular}{|c|c|c|c|c|c|c|}
\hline $\begin{array}{l}\text { Heat } \\
\text { exchanger }\end{array}$ & Type & $\begin{array}{l}\text { Duty } \\
\text { (MW) }\end{array}$ & $\begin{array}{c}P \\
\text { (bar) }\end{array}$ & Material & $\begin{array}{l}\text { Area } \\
\left(\mathrm{m}^{2}\right)\end{array}$ & $\begin{array}{c}\mathrm{FCC}^{b} \\
(\$)\end{array}$ \\
\hline \multicolumn{7}{|c|}{${ }^{a} \mathrm{~S} / \mathrm{T}$ : Shell and tube. } \\
\hline \multicolumn{7}{|c|}{${ }^{b}$ Approximate fixed capital cost with the chemical engineering plant cost index $=420$ (20). } \\
\hline $\begin{array}{l}\text { Preheater (HEX) } \\
\text { Column } 1\end{array}$ & $\begin{array}{l}\mathrm{S} / \mathrm{T}^{a} \text { Fixed } \\
\text { Tube sheet }\end{array}$ & 1.9 & 5.0 & $\begin{array}{l}\text { Carbon } \\
\text { Steel }\end{array}$ & 130 & 90,500 \\
\hline \multicolumn{7}{|l|}{ Side condenser } \\
\hline Column 1 & $\begin{array}{l}\mathrm{S} / \mathrm{T}^{a} \text { Fixed } \\
\text { Tube sheet }\end{array}$ & 2.1 & 1.5 & $\begin{array}{l}\text { Carbon } \\
\text { Steel }\end{array}$ & 130 & 93,000 \\
\hline $\begin{array}{l}\text { Total cost for } \\
\text { column } 1\end{array}$ & & & & & & 183,500 \\
\hline $\begin{array}{l}\text { Side reboiler } 1 \\
\text { Column } 2\end{array}$ & Floating head & 180.0 & 2.0 & $\begin{array}{l}\text { Carbon } \\
\text { Steel }\end{array}$ & 600 & 294,000 \\
\hline $\begin{array}{l}\text { Side reboiler } 2 \\
\text { Column } 2\end{array}$ & Floating head & 50.0 & 2.0 & $\begin{array}{l}\text { Carbon } \\
\text { Steel }\end{array}$ & 170 & 115,000 \\
\hline $\begin{array}{l}\text { Total cost for } \\
\text { column } 2\end{array}$ & & & & & & 409,000 \\
\hline
\end{tabular}

\subsection{Conclusions}

Column grand composite curves and exergy loss profiles are becoming readily available through a converged simulation of distillation columns, and enable process engineers to assess an existing operation, suggest retrofits if necessary, and determine the effectiveness of the retrofits. This study has presented the use of thermodynamic analysis for the distillation column retrofits within the separation Section of a methanol production plant. The suggested retrofits consist of an additional side condenser at stage 4 and feed preheating for column 1, and two side reboilers at stages 87 and 92, respectively for column 2. Effectiveness of the retrofits has been assessed by the improved column grand composite curves and exergy loss profiles as well as by an approximate economical analysis. After the retrofits, actual and minimum vapor flow profiles have become closer. Also the difference between the ideal and actual profiles of the enthalpies in the columns grand composite curves has become smaller. The range of reductions in the total exergy losses is $21.5 \%$ to $41.3 \%$, which causes a considerable saving in the available energy losses. The thermodynamic efficiencies also increased considerably. Therefore, the columns operate with less thermodynamic imperfections. The savings in electricity can pay back the initial cost of retrofits in a short time of operation. Implementing incentives for environmentally friendly designs may reduce the cost of the retrofits further. 


\section{References}

[1] Dhole, V. R. and Linnhoff, B. (1993) Distillation column targets, Comput. Chem. Eng., 17(56), pp. 549-560.

[2] Ognisty, T. P. (1995) Analyze distillation columns with thermodynamics, Chem. Eng. Prog., 91(2), pp. $\quad 40-46$.

[3] Bandyopadhyay, S., Malik, R. K. and Shenoy, U. V. (1998) Temperature-enthalpy curve for energy targeting of distillation columns, Comput. Chem. Engng., 22(12), pp. 1733-1744.

[4] De Koeijer, G. M. and Rivero, R. (2003) Entropy production and exergy loss in experimental distillation columns, Chem. Eng. Sci. , 58(8), pp. 1587-1597.

[5] Al-Muslim, L., Dincer, I. and Zubair, S. M. (2003) Exergy analysis of single-and two-stage crude oil distillation units, J. Energy Resource Tech. , 125(9), pp. 199-207.

[6] Al-Muslim, H. I. and Dincer, I. (2005) Thermodynamic analysis of crude oil distillation systems, Int. J. Energy Res., 29(7), pp. 637-655.

[7] Demirel, Y. (2004) Thermodynamic analysis of separation systems, Sep. Sci. Technol., 39(16), pp. 3897-3942.

[8] Seider, W. D., Seader, J. D. and Lewin, D. R. (2004) Product \& Process Design Principles 2nd ed. New York: Wiley.

[9] Demirel, Y. (2002) Nonequilibrium Thermodynamics Transport and Rate Processes in Physical and Biological Processes . Amsterdam: Elsevier.

[10] Demirel, Y. and Sandler, S. I. (2004) Nonequilibrium thermodynamics in engineering and science, J. Phys. Chem. B, 108(1), pp. 31-43.

[11] Chang, H. and Li, Jr-W. (2005) A new exergy method for process analysis and optimization, Chem. Eng. Sci., 60(10), pp. 2771-2784.

[12] Rivero, R., Garcia, M. and Urquiza, J. (2004) Simulation, exergy analysis and application of diabatic distillation to a tertiary amyl methyl ether production unit of a crude oil refinery, Energy, 29(3), pp. 467-489.

[13] Demirel, Y. and Sandler, S. I. (2001) Linear nonequilibrium thermodynamics theory for coupled heat and mass transport, Int. J. Heat Mass Transfer, 44(13), pp. 2439-2451.

[14] Doldersum, A. (1998) Exergy analysis proves viability of process modifications, Energy Convers. Mgmt., 39(16-18), pp. 1781-1789.

[15] Liu, Y. A. (2003) Process and Product Design I: Hands-on Training Course on Process Simulation, Retrofit and Optimization Using ASPEN PLUS . Virginia: Virginia Tech.

[16] Aspen Technology V11.1. Cambridge, MA: Aspen Plus 
[17] Agrawal, R. and Herron, D. M. (1998) Efficient use of an intermediate reboiler or condenser in a binary distillation, AIChE J., 44(6), pp. 1303-1315.

[18] Bandyopadhyay, S. (2002) Effect of feed on optimal thermodynamic performance of a distillation column, Chem. Eng. J., 88(1-3), pp. 175-186.

[19] Rivero, R. (2001) Exergy simulation and optimization of adiabatic and diabatic binary distillation, Energy, 26(6), pp. 561-593.

[20] Turton, R., Bailie, R. C., Whiting, W. B. and Shaeiwitz, J. A. (2003) Analysis, Synthesis and Design of Chemical Processes 2nd ed . New Jersey: Prentice Hall. 